\title{
Photochemical Preparation of Novel Tetracyclic Indenoquinolines from Benzotropolone Derivatives
}

\section{Jaime Franco, ${ }^{1}$ Carlos Tabarez, ${ }^{1}$ Shubhashis Chakrabarty ${ }^{2}$ Michael S. Croft, ${ }^{2}$ Patrick Moyna, ${ }^{1}$ and Guillermo Moyna ${ }^{1,2,3, *}$}

${ }^{1}$ Departamento de Tecnología Química, Facultad de Química, Universidad de la República, Montevideo 11800, Uruguay, ${ }^{2}$ Department of Chemistry \& Biochemistry, University of the Sciences, Philadelphia, PA 19104, USA, and ${ }^{3}$ Departamento de Química, Polo Agroalimentario y Agroindusgtrial del Litoral Oeste, Universidad de la República, Paysandu 60000, Uruguay.

*e-mail corresponding author: gmoyna@fq.edu.uy

Keywords: Indenoquinolines; Photoisomerization;Benzotropolones.

\section{INTRODUCTION}

Heteroatom-bearing tetracyclic backbones are important scaffolds for a number of biological targets. These compounds have been widely used as antimicrobial and anticancer agents, and include tetracycline antibiotics and topoisomerase inhibitors. ${ }^{1,2}$ We have shown that a novel class of tetracyclic tetraindenoquinolines could be obtained through photoisomerization of benzotropolone derivatives. $^{3}$ In this presentation we detail the preparation of a series of these compounds as well as the corresponding indenoquinolines (Figure 1), and discuss their biological evaluation.

\section{RESULTS AND DISCUSSION}

As we recently reported, Diels-Alder adducts formed between benzotropolones and nitrosobenzene can be photoisomerized in fair yields to novel tetraindenoquinolines. ${ }^{3}$ Based on these results, and on previous work carried out by our groups, ${ }^{4}$ we were able to increase the diversity of the compounds in the series. Starting form trimethylpurporogallin, a series of aliphatic and aromatic ethers were prepared using standard Williamson conditions. These were subsequently treated with nitrosobenzene to afford a series of Diels-Alder adducts bearing endocyclic $-\mathrm{N}-\mathrm{O}$ - bonds. As shown in Figure 1, phoisomerization of these oxazines leads to the novel tetrahydoindenoquinoline frameworks. Planar aromatic tetracyclic systems can then be readily obtained by oxidation. In addition, a the preparation of a number of amide derivatives based on one of these compounds is also described. Preliminary biological data indicated that some of these compounds have $\mu \mathrm{M}$ activity against cervical (HeLa), ovarian (A2780), endometrial (Ishikawa), and lung (SW1573) cancers.

\section{CONCLUSION}

The preparation of novel tetracyclic indenoquinolines through photoisomerization of readily available benzotropolone derivatives is described. Their biological activity and potential mode of action is also briefly discussed.<smiles>COc1cc2cccc(OC)c(=O)c2c(O)c1OC</smiles>

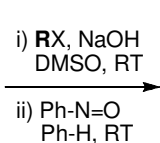<smiles>COc1cc2c(c(O)c1OC)C(=O)C1(OC)CCC2N(c2ccccc2)O1</smiles><smiles>COc1cc2c(c(O)c1OC)C(=O)[C@H]1[C@@H]2Nc2ccccc2[C@H]1C(C)=O</smiles><smiles>COc1cc2c(c(OC)c1OC)C(=O)c1c-2nc2ccccc2c1C(C)=O</smiles>

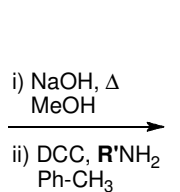

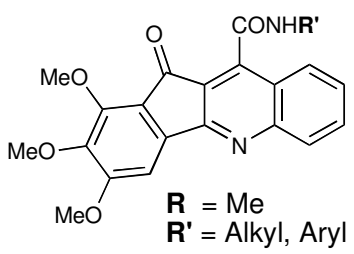

Figure 1. Synthetic route to tetracyclic indenoquinoline and and tetrahydroindenoquinoline libraries.

\section{ACKNOWLEDGEMENTS}

Financial support from ANII, CSIC, Merck/AAAS USRP, NSF, and RSC is acknowledged.

\section{REFERENCES}

1) Hochstein, F. A.; Stephens, C. R.; Conover, L. H. ; Regna, P. P.; Pasternack, R.; Gordon, P. N. ; Pilgrim, F. J.; Brunings, K. J.; Woodward, R. B. J. Am. Chem. Soc. 1953, 75, 5455-5475.

2) Lown, J. W. Pharmacol. Ther. 1993, 60, 185-214.

3) Tabarez, C.; Waterman, C.; Rapp, A. L.; Moyna, P.; Moyna, G. Tetrahedron Lett. 2009, 50, 7128-7131.

4) Khrizman, A.; Slack, R. D.; Remsing, R. C.; Little, S.; Yardley, V.; Moyna, G. Arch. Pharm. 2007, 340, 569-576. 